\title{
INCREASED IL-27 SERUM LEVELS IN PATIENTS WITH SYSTEMIC SCLEROSIS AND ASSOCIATION WITH
} ESOPHAGEAL DYSMOTILITY

Anderson Rodrigues de Almeida (Universidade Federal de Pernambuco, Recife, PE, Brasil), Andréa Tavares Dantas (Universidade Federal de Pernambuco, Recife, PE, Brasil), Maria Eduarda de Oliveira Gonçalves (Universidade Federal de Pernmabuco, Recife, PE, Brasil), Rafaela Silva Guimarães Gonçalves (Universidade Federal de Pernambuco, Recife, PE, Brasil), Moacyr Jesus Barreto de Melo Rego (Universidade Federal de Pernambuco, Recife, PE, Brasil), Angela Luzia Branco Pinto Duarte (Universidade Federal de Pernambuco, Recife, PE, Brasil), Ivan da Rocha Pitta (Universidade Federal de Pernambuco, Recife, PE, Brasil), Dulcineia Saes Parra Abdalla (Universidade de São Paulo, São Paulo, SP, Brasil), Maira Galdino da Rocha Pitta (Universidade Federal de Pernambuco, Recife, PE, Brasil)

\section{BACKGROUND}

Systemic sclerosis (SSc) is a connective tissue disorder characterized by progressive cutaneous and visceral fibrosis. It is known that innate and adaptive immune systems are dysregulated in SSc, but little is known about the mechanisms involved in immune system cell dysfunction. T cells and their cytokines play roles of great importance in the pathophysiology of SSc. Interleukin 27 (IL-27) is a member of the IL-12 family which exhibits pro- and anti-inflammatory properties. Thus, in the present study we evaluated the serum levels of IL-27 in SSc patients and the possible associations and correlations with the clinical manifestations of the disease.

\section{MATERIALS AND METHODS}

Seventy-eight SSc patients and seventy-eight healthy controls matched for sex and age were included in the present study. All patients fulfilled the 1980 ACR preliminary classification criteria for SSc or 2013 ACR/EULAR criteria. Clinical and laboratory parameters were recorded down from the medical charts. Peripheral blood samples were collected from all subjects and the serum was separated for analysis. IL27 levels were quantified by enzyme-linked immunosorbent assay (ELISA) (R\&D) and the results were assessed by Mann-Whitney test and Spearman correlation test.

\section{RESULTS}

SSc patients had significantly elevated serum IL-27 levels when compared with healthy subjects (median 5.900 and $3.858 \mathrm{pg} / \mathrm{ml}$, respectively) $(p=0.001)$. In the evaluation of possible associations and correlations with clinical parameters of the disease, it was observed that patients with esophageal dysmotility presented higher IL-27 levels (median $6.471 \mathrm{pg} / \mathrm{ml}$ ) when compared to patients without this manifestation (median $3.329 \mathrm{pg} / \mathrm{ml})(\mathrm{p}=0.027)$. No associations or correlations were observed with the other clinical manifestations.

\section{CONCLUSION}

SSc patients show an increase in serum IL-27 levels and an association with esophageal dysmotility, which may reinforce the cytokine's role in the disease and the possible participation in fibrotic involvement. 